\section{Cartografia como metodologia: Uma experiência de pesquisa em Artes Visuais}

Cartography as methodology:

A research experience in Visual Arts

Resumo: Este artigo apresenta noções introdutórias acerca do uso da cartografia no desenvolvimento de uma pesquisa de mestrado em Artes Visuais. Entende a mesma como um método que entrecruza pesquisador/artista e obra, tendo sua ênfase no processo criador. Apresenta formas através das quais a cartografia poderá contribuir como método de pesquisa em um campo poético sensível, em uma poética visual e escrita para o desenvolvimento de uma pesquisa. Para isto, pensa a origem da cartografia, discorre sobre a mesma como método de pesquisa, chegando à apresentação do método aplicado à pesquisa da autora.

Palavras-chave: Cartografia; Metodologia; Artes Visuais; Arte Contemporânea; Arte e Tecnologia

Abstract: This paper presents introductory notions about the use of cartography in the development of masters research in Visual Art. It understands the same as a method that criss-crosses researcher/artist and artwork, with emphasis on the creative process. We present forms in which cartography can contribute as a research of research. To this end we reflect on the arigin of cartography the development of research. To this end, we reflect on the origin of cartography, discussing it as a the author.

Keywords: Cartography; Metodology; Visual Art; Contemporary art; Art and Technology

\section{DARALELӨ3I}

O presente artigo propõe que se pense a cartografia como metodologia de pesquisa. Apresenta noções iniciais sobre este método, sobretudo no que se refere à pesquisa em arte. Pensa a cartografia entendida como prática, mais do que como metodologia científica. Em cartografia, o que interessa é o que se passa entre, o que extrapola fronteiras, o que transborda as bordas, as delimitações. Busca-se pensar e sentir o processo, sendo o pesquisador o agente que se coloca como pesquisa juntamente com seu objeto.

A cartografia como método de pesquisa, foi introduzida pelos filósofos Gilles Deleuze e Félix Guattari, através de cinco volumes, que compõem os Mil Platôs: capitalismo e esquizofrenia, publicados pela primeira vez no Brasil em 1995. O conceito de cartografia tem sua origem na geografia, e o que os autores fazem, é trazê-lo para outros campos de conhecimento. Segundo Luciano Bedin da Costa,

\section{O que os filósofos querem é pensar a realidade através de outros dispositivos que não os apresentados tradicionalmente pelos discursos científicos, valorizando aquilo que se passa nos formados e criadores de realidade (COSTA, 2014, p. 69-70).}

Esta leitura propõe que pensemos agora nas imagens dos mapas cartográficos. Detenhamo-nos nas composições das representações cartográficas, observando suas linhas, em seus mais variados modos de apresentação: retas, curvilíneas, cruzadas, transpassadas, traçadas. Com essa imagem de mapas, em mente, podemos iniciar o movimento de compreensão da metodologia Cartográfica.

Se a cartografia como ciência trabalha com territórios e suas representações, de modo semelhante, opera-se com a metodologia cartográfica. Toda pesquisa opera em campos, em territórios de naturezas distintas: filosóficos, sociais, artísticos, sentimentais, e assim 
por diante, e nestes territórios, encontra-se o pesquisador, que transita por entre os territórios possíveis em uma pesquisa. Neste caminho, traça uma existência que nunca é única, pois é permeada por estas camadas, por estes pontos de encontro de territórios. O método cartográfico propõe que se trabalhe com o entre, sugere que a pesquisa acontece no que se vivencia entre o pesquisador e o território de pesquisa. O que vive um pesquisador-cartógrafo, reside exatamente no ato de cartografar o que é móvel, o que não é estático: ele captura o entre, em seus campos de abrangência.

Primeiramente, precisamos entender que a cartografia não é um método fechado, e principalmente, ela não aponta passos, ela não é um método pronto. $O$ que os autores fazem é nos sugerir pistas, e que operemos com elas da maneira que nos for conveniente, que nos for útil.

Uma das principais características deste método de pesquisa encontra-se na atenção que devemos dar às perguntas que a cartografia nos coloca. Isso significa que ao utilizar a metodologia cartográfica, o pesquisador coloca-se, e, sobretudo, percebe-se dentro de sua pesquisa. É como o cartógrafo que confecciona um mapa: ele precisa estar inserido no território que projeta, para poder projetar. Este é um dos princípios da cartografia, o autor presente em sua pesquisa, em sua totalidade.

No método cartográfico, não buscamos um resultado, uma conclusão de fatos, e sim, pensamos o próprio processo de pesquisa, em si: suas etapas, seus desvios, seus "erros", e tudo que dali puder vir a se tornar potência para a pesquisa.

Ao trabalhar com a metodologia cartográfica, o pesquisador será quem decide seus passos, seus métodos, suas interações com a pesquisa. Múltiplos são os meios de pesquisar através da cartografia, e como isto vai acontecer dependerá do pesquisados, que ao decorrer da pesquisa passará a compô-la juntamente com seu objeto.

Segundo Costa (2014, p. 72) "Se pudéssemos apresentar um elemento fundamental para uma prática cartográfica, este seria o encontro". O encontro, da maneira que ele coloca, é apresentado como movimento, como algo da ordem do inusitado. O encontro é algo que não acontece em linha reta, acontece entre dois ou mais elementos, onde sobrevoa todos os campos que compõem seu múltiplo território de pesquisa. Ainda segundo o autor, "Neste sentido, tudo é passível de gerar um encontro cartográfico. As coisas aparentemente mais insignificantes e imprevisíveis podem ser extremamente potentes" (p. 72).

É nesse sentido, que este método se encontra com as imagens de mapas, sugeridas para que pensássemos, no início deste capítulo. Pensar nos movimentos de pesquisa como diversas linhas sem começo nem fim, diversos movimentos onde estas linhas de percurso se tocam, compondo novas linhas, novos mapas, novas territorialidades de pensamento. Inserir-se neste mapa, nestes traçados, e estar atento aos desvios das linhas. Produzir a partir dos desvios. Pretende-se que se visualize o método de pesquisa como a representação de um mapa cartográfico.
(...) O mapa é aberto, é conectável em todas as suas dimensões, constantemente. montagens de qualquernatureza, serpreparado porumindivíduo um grupo, uma formação social." (DELEUZE, 2000, p.22).

É preciso dizer que este método vem sendo utilizado nos mais diferentes campos de pesquisa e atuação, principalmente nas ciências humanas, na psicologia, na saúde e no campo da educaçã́o, que abrange uma quantidade significativa de áreas do conhecimento. Por ter este caráter aberto de pesquisa, o método pode ser interpretado 
em diferentes áreas, aproximando pesquisador e pesquisa e possibilitando outros modos de trabalhar com o inesperado.

\section{O MÉTODO CARTOGRÁFICO NA PESQUISA EM ARTES.}

Inúmeras são as abordagens utilizadas pelos pesquisadores em arte, através da metodologia cartográfica. Alguns buscam na cartografia uma estética para suas obras, trabalhando com representações. Outros encontram aproximação pelo caráter desviante, e aplicam a teoria do método em sua poética de criação. Outros, ainda, utilizam a metodologia para organizar seu pensamento, sua linha de raciocínio. Encontram logica nos cruzamentos de linhas que se encontram. Fato é que a cartografia se mostra eficiente dentro da pesquisa poética, seja qual for a forma escolhida de abordagem. Cartografar é perceber a pesquisa através da experiência, do devir, de estar aberto ao encontro e trazer isso à tona, de maneira poética.

Para entendermos algumas das abordagens possíveis, podemos analisar a obra da artista gaúcha Kelly Wendt. Ao apreender imagens fotográficas da cidade na qual habita, encontra materialidade para sua pesquisa (Figura 2)

Sua metodologia consiste em longas caminhadas pela cidade de Pelotas, nas quais ela fotografa e cataloga as casas abandonadas que encontra em seus percursos.

A referência cartográfica certamente encontra-se em sua metodologia andante, que perambula pela cidade, construindo linhas imaginárias, mas também apresenta-se de maneira muito clara em sua obra visual.

Em outro exemplo, pode-se pensar o método cartográfico aplicado ao processo de criação, modo em que será operado na pesquisa da autora, na qual a cartografia não aparecerá enquanto imagem em si. Pretende-se utilizar o método cartográfico, classificando esta

DARALELӨ31 metodologia como uma cartografia das sensações.

Em seu trabalho de mestrado, a autora pesquisa a temática do tempo. Pensa o tempo como duração, operando com este conceito de Henri Bergson. Trata-se de pensar o tempo de uma forma não linear, não cronológica, não contabilizável, mas como um todo composto por tempos sobrepostos. Na pesquisa, se pensa as inúmeras formas em que sentimos o tempo, em que percebemos, ou não, sua ação.

A autora propõe que se atente às sensações temporais. Ao trabalhar com a linguagem da videoarte, pretende construir uma instalação imersiva, ao final desta pesquisa. Pretende imergir o espectador em um tempo distinto do tempo habitual, trabalhar com acelerações/ desacelerações, desse tempo. Que no espaço da instalação, o espectador perca sua noção habitual de tempo.

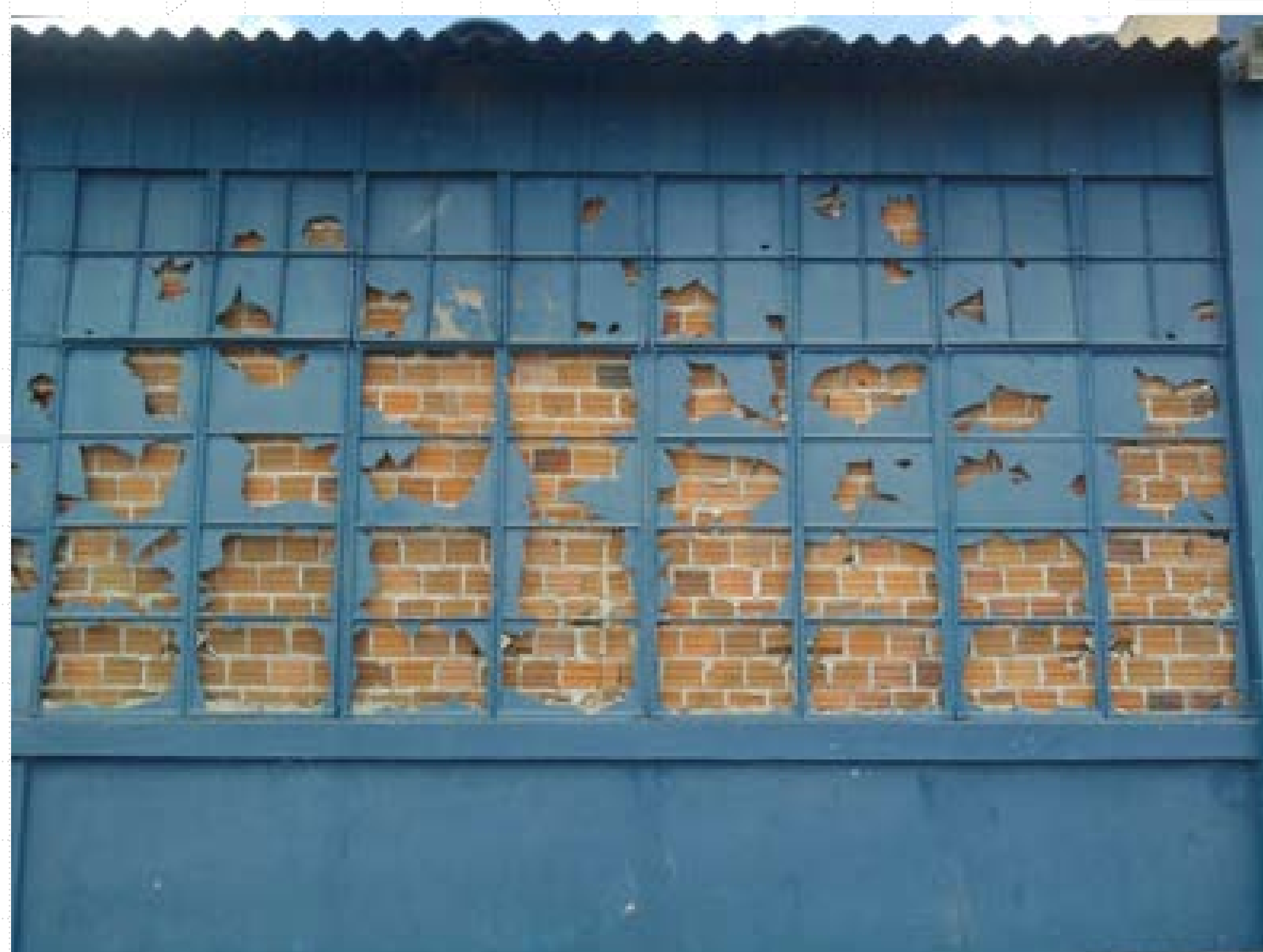

Figura 2- Janela Azul, fotografia, 2011. Autora: Kelly Wendt.

Disponível em: http://deolhoscerrados.blogspot.com.br. Acesso em: 20/08/2017. 


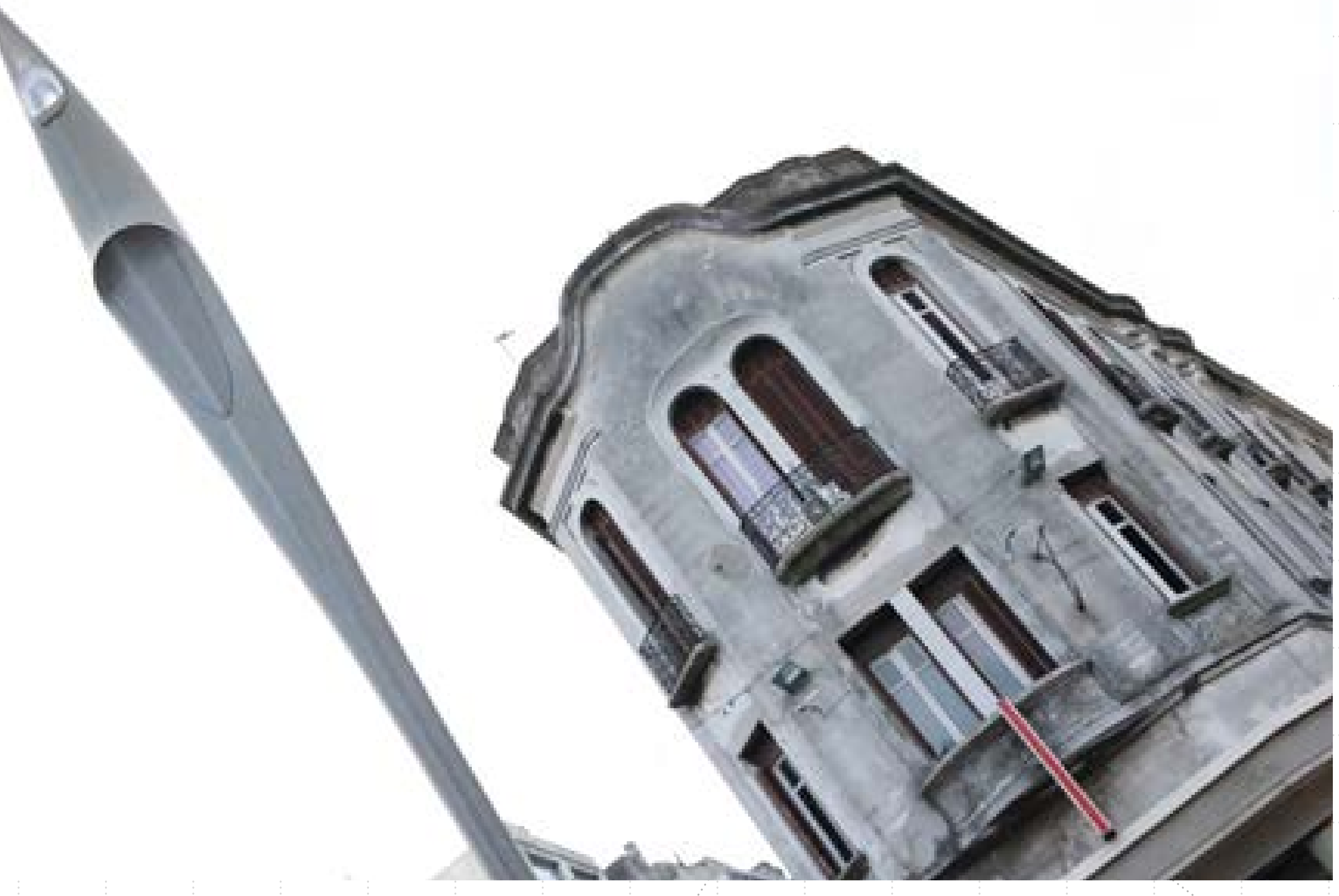

A pesquisadora encontra-se com a cartografia ao trazer ao seu método de pesquisa, uma prática que denominou como deriva. Nesta, ambula sem destino pelas ruas das cidades, atenta às sensações causadas por estes lugares. Busca pelo desconhecido, transita cidades desconhecidas, ou locais desconhecidos por ela, na cidade na qual habita. Destes locais, captura imagens, compondo-as com suas sensações. Enquadra imagens a partir da sensação, aberta aos acasos, transitando no que existe entre a intenção e o acaso proporcionado pela prática da deriva.

Cartografar sensações? Produzir a partir das sensações experimentadas sob a atmosfera de cada cidade escolhida (Figura 4). Imagens em movimento, fotografias, áudios e escritos, disparados por camadas de sensações. Um mapeamento de sensações experienciadas no caminho, no trajeto, em cada lugar específico. Vento, chuva, neblina. Um corpo que sente e que pulsa. Um corpo imóvel, transbordando, ora silêncios, ora movimentos da ordem do sentir.

Figura 3: Fotografia digital, edificação parcialmente abandonada, Montevideo,

Uruguai, 2017. Autora: Indira Z. Richter

Para a realização desta instalação, utilizará diversos meios de imergir o público, através de diversas percepções sensoriais: temperatura, aromas, sons e instalações de vídeo e fotografia expandida. Pretende que a instalação traga elementos analógicos em sua estrutura: televisões de tubo, videocassetes, fitas VHS.

A poética visual desta proposta traz em si algo de sombrio, de essência soturna, de ares melancólicos. Para isto, as imagens capturadas pela autora, tanto em vídeo quanto em fotografia, estão sendo produzidas em lugares abandonados, prédios esquecidos, construções em ruínas (Figura 3). Há também algo sobre vultos (Figura 5). A figura humana aparece através do som, e sutilmente através da imagem.

PARALELO3!



Figura 4 - Fotografia digital, Praia do Laranjal, Pelotas, Rio Grande do Sul. Autora: Indira Z. Richter 


\section{REFERÊNCIAS BIBLIOGRÁFICAS}

BERGSON, Henri. Matéria e Memória: ensaio sobre a relação do

corpo com o espírito. São Paulo: Martins e Fontes, 2006

COSTA, Luciano B. Cartografia: uma outra forma de pesquisar. Revista Digital do LAV - Santa Maria : vol. 7, n.2, p. 66-77 - mai./ago.2014.

DELEUZE, Gilles; GUATTARRI, Félix. Mil Platôs: capitalismo e

esquizofrenia, vol. 3. Tradução de Aurélio Guerra Neto, Ana Lúcia de

Oliveira, Lúcia Cláudia e Suely Rolnik. São Paulo: Ed. 34, 1996.

GUATTARI, Félix; ROLNIK, Suely. Micropolíticas: cartografias

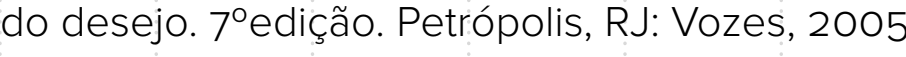

ROLNIK, Suely. Cartografia Sentimental. Transformações contemporâneas do desejo. São Paulo: Editora Estação Liberdade, 1989. 